\title{
Intraocular matrix metalloproteinase 2 and 9 in patients with diabetes mellitus with and without diabetic retinopathy
}

\author{
Anna B. Kłysik ${ }^{1}$, Julia Naduk-Kik², Zbigniew Hrabec², Roman Goś1, Elżbieta Hrabec ${ }^{2}$
}

1Department of Ophthalmology, Medical University of Lodz, Lodz, Poland 2Department of Medical Enzymology, Medical University of Lodz, Lodz, Poland

Submitted: 27 April 2009

Accepted: 11 June 2009

Arch Med Sci 2010; 6, 3: 375-381

DOI: 10.5114 /aoms.2010.14258

Copyright $\odot 2010$ Termedia \& Banach

\author{
Corresponding author: \\ Anna B. Kłysik, MD \\ Department \\ of Ophthalmology \\ Medical University of Lodz \\ Zeromskiego 113 \\ 90-549 Lodz, Poland \\ Phone: +48 426393634 \\ E-mail: aniaklysik@wp.pl
}

\begin{abstract}
Introduction: We aimed to investigate activities of metalloproteinases 2 (MMP-2) and MMP-9 in aqueous humour of patients with diabetes mellitus with various stages of diabetic retinopathy.

Material and methods: We included 36 samples of aqueous humour of patients suffering from diabetes mellitus, undergoing routine cataract surgery. Seven of them suffered from proliferative diabetic retinopathy (PDR), 3 had diabetic maculopathy and the remaining 26 had background or minimal background retinopathy only. Metalloproteinases 2 and MMP-9 activities in aqueous humour were measured by gelatin zymography combined with the densitometric imaging system. Total protein content in aqueous humour samples was also assessed. Results: Metalloproteinases 2 activities were present in almost all samples of aqueous humour (32 of 36 ) and were 2.6-fold higher in patients who suffered from diabetic ocular complications ( $p<0.0001)$. Activities of MMP-2 correlated well with the duration of the disease (correlation $=0.37, p=0.03$ ) and tended to correlate with total protein levels in aqueous humour (correlation $=0.43$, $p=0.06$ ). Metalloproteinases 9 activities were observed only in 2 of 7 patients with proliferative diabetic disease and the enzyme was absent from aqueous humour samples of patients without proliferative retinopathy.

Conclusions: Increased activities of MMP-2 in aqueous humour of patients with PDR may be related to the disease process and support the hypothesis that MMP-2 may be of particular importance in diabetic retinal neovascularization. MMP-9 may be activated at a certain disease stage only.
\end{abstract}

Key words: metalloproteinase 2, metalloproteinase 9, aqueous humour, diabetic retinopathy, diabetes mellitus, zymography.

\section{Introduction}

Extracellular matrix (ECM) undergoes a constant remodelling in health and disease states. Matrix metalloproteinases (MMPs) are a family of calciumactivated, zinc-containing enzymes that are involved in turnover and remodelling of the ECM and collectively are capable of breaking down most, if not all, protein components of the ECM, including collagens, laminin, fibronectin, elastin, and other constituents [1]. However, MMPs are also able to degrade a number of non-ECM proteins including growth factors, chemokines, cytokines and some surface receptors [2]. Metalloproteinases are involved in a number of both physiological and pathological processes, 
including trophoblast implantation, morphogenesis, tissue remodelling, inflammation, cancer growth and metastasis, and what is more, the enzymes may participate in neovascularization [3-5]. Breakdown of basement membrane is believed to be an important step for angiogenesis, and both MMP-2 and MMP-9 can degrade basement membrane type IV collagen as well as facilitate vascular invasion and tubule formation [6, 7]. Furthermore, MMP-2 and MMP-9 are able to degrade pigment epithelium-derived factor (PEDF), a 50-kDa glycoprotein highly expressed in the retinal pigment epithelium and which is the principal antiangiogenic protein of the eye [8].

Interactions between cells of the human body and extracellular matrix are very important in the pathogenesis of eye diseases. Metalloproteinase 2 and MMP-9 belong to the group of type IV collagenases that play an important role in new vessel formation and were previously found to be upregulated by vascular endothelial growth factor (VEGF), in relation to artherosclerotic plaque revascularization [9]. Activation of the neovascular response is an important event in the development of diabetic eye disease, although possibly in many ways different from pathological neovascularization elsewhere in the body. Increased levels of pro-MMP-9 and activated MMP-9 have previously been found in the vitreous of patients with PDR associated with vitreous haemorrhage [10]. The same study did not reveal any correlation between serum and vitreous concentrations of MMP-2 and MMP-9 in both proenzyme and activated form. However, increased systemic values of MMP-9 and MMP-9/TIMP-1 ratio were found in type 1 diabetic subjects compared to healthy subjects. Plasma levels of MMP-9 were also significantly higher in the group of patients with type 1 diabetes and developing PDR compared to diabetics without retinopathy [11].

Potentially, MMPs may also play a role in the early stages of diabetic retinopathy, which involves breakdown of the blood-retinal barrier and destruction of endothelial cell tight junctions [12].

Table I. Characteristics of subjects in the two groups

\begin{tabular}{|lcc|}
\hline & \multicolumn{1}{c}{$\begin{array}{c}\text { Diabetes } \\
\text { mellitus without } \\
\text { retinopathy }\end{array}$} & $\begin{array}{c}\text { Proliferative diabetic } \\
\text { retinopathy } \\
\text { and maculopathy }\end{array}$ \\
\hline $\begin{array}{l}\text { Age } \\
\text { (years with range) }\end{array}$ & $71(52-91)$ & $75(58-86)$ \\
\hline Gender $\mathrm{M}: \mathrm{F}$ & $11: 15$ & $5: 5$ \\
\hline $\begin{array}{l}\text { Body weight } \\
\text { (kg with range) }\end{array}$ & $87(68-110)$ & $88(78-98)$ \\
\hline $\begin{array}{l}\text { Ischaemic heart } \\
\text { disease }\end{array}$ & $12 \%$ & $10 \%$ \\
\hline Stroke & $4 \%$ & 0 \\
\hline
\end{tabular}

As diabetic changes in the blood vessels concern the anterior segment of the eye as well as the posterior, we aimed to investigate aqueous humour of diabetic patients. In the present study we investigated activities of MMP-2 and MMP-9 in aqueous humour of patients with diabetes mellitus of type 1 and type 2 without retinopathy, with diabetic maculopathy and with PDR.

\section{Material and methods}

\section{Subjects}

The study protocol was approved by the ethics committee of the Medical University of Lodz and was conducted according to the Helsinki Declaration. All patients gave their full informed consent.

We included 36 (52 to 91 years of age; mean \pm SD $72.1 \pm 9.4$ years) subjects undergoing routine cataract surgery at the Ophthalmology Department of the Medical University of Lodz, with diabetes mellitus of the duration of 2 years or longer. Seven of them suffered from PDR, 3 had diabetic maculopathy and the remaining 26 had background or only minimal background retinopathy. Thus, 10 of them suffered from diabetic ocular complications (PDR and diabetic maculopathy).

Diabetes mellitus was diagnosed according to the criteria of the American Diabetic Association. Patients suffering from confirmed diabetes mellitus for less than 2 years and patients suffering from other ocular pathologies including glaucoma were excluded from the experiment. Subjects with malignant neoplastic diseases, and acute and chronic inflammatory diseases of the respiratory tract were also excluded from this study. Exclusion of patients with any ocular pathology, other than cataract and diabetic retinopathy, was necessary to avoid alternation of aqueous humour content by elevated protein levels, blood, haemolysed blood and inflammatory cells. All patients underwent surgery in the morning and were fasting (Table I).

\section{Preparation of aqueous humour samples}

Samples of aqueous humour were taken at the beginning of cataract surgery after performing paracentesis into a sterile tube and frozen immediately at $-70^{\circ} \mathrm{C}$ until assay. Paracentesis was performed by standard clear corneal technique, by a single surgeon, to avoid any contamination of the sample by blood or tear fluid. Specimens were transported in dry ice.

\section{Preparation of plasma samples}

Venous blood samples were collected into heparin tubes (Vacuette ${ }^{\circledR}$-Greiner Labortechnik), centrifuged at $2000 \mathrm{RCF}$ for $15 \mathrm{~min}$ at $4^{\circ} \mathrm{C}$, and 
plasma samples were mixed with glycerol in a $1: 1$ ratio (per weight) and stored at $-70^{\circ} \mathrm{C}$ until assay.

\section{Protein assay}

Total protein concentration in aqueous humour specimens was measured using the Ohnishi and Barr method [13]. Serum bovine albumin was used as a standard. The assay was done in triplicate.

\section{Gelatin zymography}

Type IV collagenases were investigated in aqueous humour samples by means of gelatinembedded polyacrylamide gel electrophoresis followed by incubation. The specimens were placed on zymographic gels in a random manner because the scientists who analysed the samples were not aware of the clinical history of the patients.

Gelatin zymography was performed as described previously [14]. An aliquot of aqueous humour was dissolved in electrophoresis sample buffer and subjected to electrophoresis in $10 \%$ polyacrylamide gel embedded with $1.5 \mathrm{mg} / \mathrm{ml}$ denatured type I collagen (gelatin) in the absence of $\beta$-mercaptoethanol. After electrophoresis the enzymes were renatured by incubation with $2.5 \%$ Triton X-100 and the enzyme reaction was carried out at $37^{\circ} \mathrm{C}$ for $21 \mathrm{~h}$ in a buffer containing $50 \mathrm{mM}$ Tris- $\mathrm{HCl}, \mathrm{pH} 7.4,10 \mathrm{mM} \mathrm{CaCl}, 3 \mathrm{mM} \mathrm{NaN}_{3}$. Thereafter, the gels were stained for $1.5 \mathrm{~h}$ with $0.0125 \%$ Amido Black in $7 \%$ acetic acid and 20\% ethanol. Type IV collagenases were visualized without destaining as transparent bands against the dark blue background of Amido Black-stained slab gels. The assays were done in triplicate.

\section{SDS polyacrylamide gel electrophoresis (SDS-PAGE)}

Electrophoresis of aqueous humour and plasma proteins in $10 \%$ polyacrylamide gels was carried out using the method of Laemmli [15] and proteins were visualized by silver staining according to the protocol described by Wray et al. [16].

\section{Quantification of type IV collagenase levels and statistical analysis}

For quantitative purposes the aqueous humour specimens were electrophoresed in zymographic gels and MMP-2 activities were calculated by comparison of their IOD with the average IOD value of the plasma MMP-2 derived from the same individual, used as a standard. Metalloproteinase-2 activities were expressed in arbitrary units. The experiments were performed in triplicate.

Zymographic gels were captured using a video camera (Image Master VDS, Pharmacia Biotech) and images were analysed with Image Master VDS software. Computer-assisted analysis (with Image Master VDS software) of MMP-2 and MMP-9 lysis bands from serial dilution of commercial enzymes performed previously revealed a linear correlation of integrated optical density (IOD) with MMP activities. The linearity was observed within a broad range of activities (IOD values: from $5 \times 10^{4}$ to $25 \times 10^{4}$ for MMP-2 and from $1 \times 10^{4}$ to $12 \times 10^{4}$ for MMP-9) [14]. Thus, in the current study, we operated within the range of IOD in question.

For the quantitative analysis internal standards were electrophoresed on two lines in each gel and MMP activities tested were calculated by comparison of their IOD with the average IOD value of MMP standards. As for the standards, the equivalent of $0.4 \mu \mathrm{l}$ of normal plasma was subjected to gelatin zymography. The identity of plasma MMP-2 and MMP-9 was checked previously, and was based on their co-migration with standard human MMP-2 and MMP-9 (Boehringer-Mannheim) and was confirmed by incubation of the zymographic gels in the presence of an MMP inhibitor. Both enzymes were entirely inhibited in the presence of $0.1 \mathrm{mM}$ EDTA, a calcium ion chelator [17]. Previous experiments demonstrated that the plasma specimens $(n=3)$ revealed $90 \%$ coincidence in MMP-2 and MMP-9 activities when tested after 2,4 , and 6 months' storage at $-70^{\circ} \mathrm{C}$.

\section{Statistical analysis}

Statistical analyses were performed using Student's t-test. Correlations were determined using Spearman's correlation coefficient.

\section{Results}

Zymographic analysis revealed the presence of MMP-2 in almost all aqueous humour samples tested (32 of 36), whereas MMP-9 activity was observed only in 2 patients with active proliferative disease. The identity of these activities was based on their co-migration with MMP-2 and MMP-9 derived from normal plasma (used as a standard). An example of such a zymogram is presented in Figure 1.

As shown in Figure 2 the MMP-2 activities were 2.6-fold higher in the aqueous humour of subjects with diabetic ocular complications (PDR, and diabetic maculopathy) than in diabetic patients without such complications (160.3 \pm 39.5 vs. 60.7 \pm 16.4 , mean $\pm 95 \%$ confidence interval, $p<0.0001$ ). We also found that MMP-2 levels were significantly correlated with the duration of the disease $(p=0.03$, correlation coefficient $=0.37)$ (Figure 3$)$. Total protein concentration in aqueous humour specimens was also measured.

In spite of the fact that total protein concentration in aqueous humour specimens of 


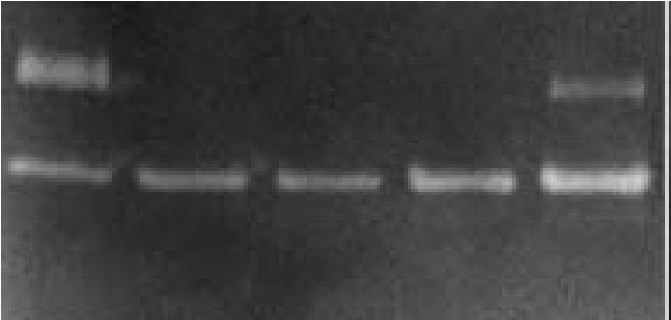

a

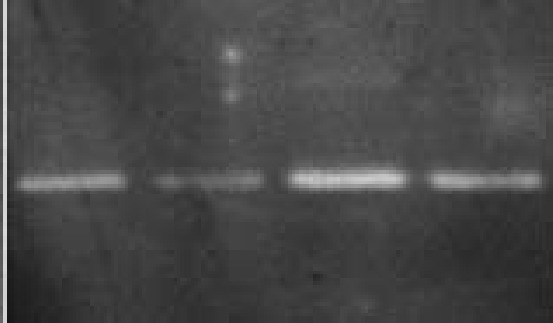

h

MMP-9 $(92 \mathrm{kDa})$

MMP-2 (72 kDa)

Figure 1. Gelatin zymography of the aqueous humour samples. Lanes: (a) serum sample (standard); (b, c, g) diabetes mellitus patients free of ocular complications; (d-f, h, i) PDR patients

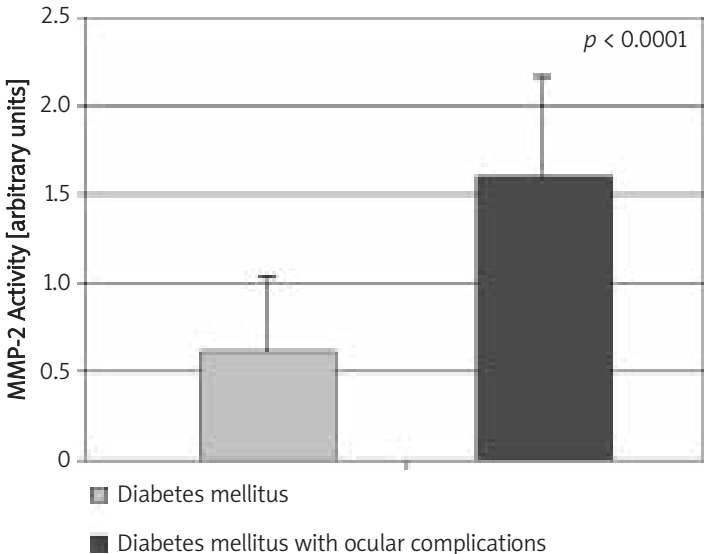

Figure 2. Activities of MMP-2 in the aqueous humour samples of diabetes mellitus patients. (Student's $t$ test). Shown are mean values $\pm \mathrm{SD}$

subjects with diabetic ocular complications was twofold higher than in patients without such complications, the result was insignificant, probably due to too few patients being included in this study. However, MMP-2 activities in aqueous humour tend to correlate with the total protein concentrations $(p=0.06$, correlation coefficient $=0.43)$ (Figure 4$)$.

Because MMP-9 activity was observed only in 2 of 36 aqueous humour samples, we decided to find out whether aqueous humour of diabetic patients contains any proteins of molecular mass similar to MMP-9. For this reason, aqueous humour and plasma proteins were electrophoresed on $12 \%$ polyacrylamide gels, according to the procedure described by Laemmli [15]. The electrophoretic pattern shown in Figure 5 indicates that abundant plasma proteins (HSA, IgG heavy chain, and many other high molecular proteins) are visible in the aqueous humour specimens. Qualitative composition in relation to abundant proteins of aqueous humour and plasma is similar.

\section{Discussion}

Our study demonstrates increased levels of activity of MMP-2 in the aqueous humour of

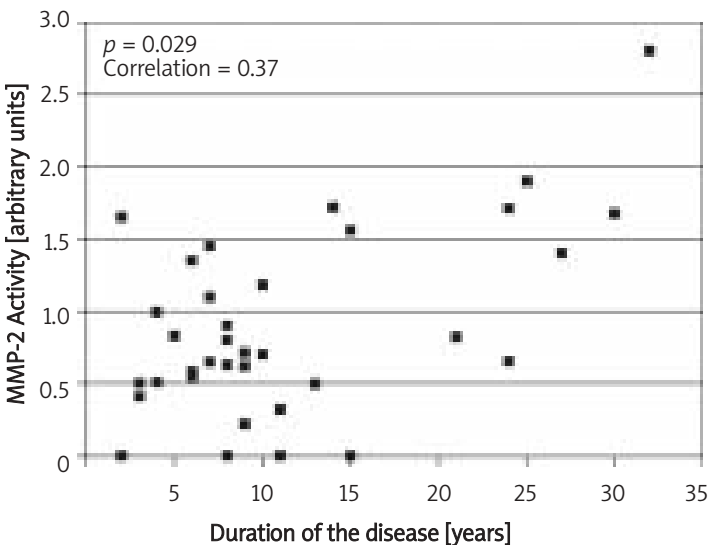

Figure 3. Correlation between the duration of the disease and MMP-2 activity in aqueous humour of diabetes mellitus patients (Spearman's rank correlation test)

subjects with proliferative diabetic retinopathy and diabetic maculopathy as compared to diabetic patients free of diabetes-related ocular complications. Metalloproteinase- 9 activities were also visible in a few aqueous humour specimens of PDR patients and the enzyme was absent from patients without such complications. We aimed to investigate activity levels and not overall concentration levels of type IV collagenases (MMP-2 and MMP-9). To the best of our knowledge this is the first study demonstrating increased levels of MMP-2 in aqueous humour of patients suffering from diabetic retinopathy. Moreover, in relation to type IV collagenases the results of our investigations showed the selective increase of MMP-2 only in proliferative retinopathy samples.

Gelatin zymography is a very well established method for examining MMP-2 and MMP-9 in cells and tissue extracts, serum, plasma and various other samples. Gelatin zymography has very high specificity and extremely high sensitivity for type IV collagenases, namely MMP-2 and MMP-9. The detection limit for MMP-9 has been reported to be $32 \mathrm{pg}$ [18]. In our previous study we showed that mean intra-assay variation $(n-5)$ was $6.8 \%$ for 


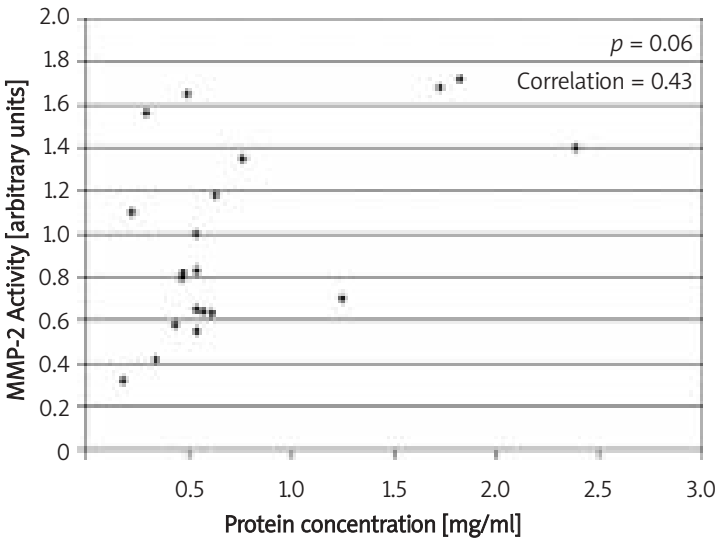

Figure 4. Correlation between the concentration of the protein and MMP-2 activity in aqueous humour of diabetes mellitus patients (Spearman's rank correlation test)

MMP-2 and 7.5\% for MMP-9. The mean inter-assay variation was $15.4 \%$ for MMP-2 and $17.3 \%$ for MMP-9 [19].

Noda et al. [20] found that vitreous proliferative membranes in diabetic retinopathy, in addition to high MMP-9, contain high levels of MMP-2. Increased levels of MMP-9 were previously reported in vitreous humour and fibrovascular membranes of PDR patients [21, 22]. Noda et al. [20] demonstrated for the first time that among different MMPs (including MMP-1, MMP-2, MMP-3, MMP-7, MMP-8, MMP-9, and MMP-13) examined in the vitreous samples only the levels of MMP-2 and MMP-9 are significantly augmented in the PDR eyes. Other studies have shown that both MMP-2 and MMP-9 are present in the vitreous samples of PDR patients but only MMP-9 is elevated in PDR [23-25]. Furthermore, it has been shown that MMP-9 levels correlate with disease progression, though most of the MMP-9 is in the pro-enzyme form. The source of this latent form of MMP-9 is unknown but it seems to be a marker of disease progression. The data indicated that MMP-9 may be actively involved in pathology of proliferative retinopathy [26]. This is further supported by observations that microvascular endothelial permeability is increased in the presence of this enzyme [19, 23]. Das et al. [26] revealed that human diabetic neovascular membranes contain high levels of type IV collagenases. MMP-2 and MMP-9 in their pro-enzyme form were significantly elevated in the neovascular membranes in comparison with normal retinas. In addition, the active type IV collagenases were present in the neovascular membranes, whereas there was no detectable level of the active forms of these enzymes in normal retinas [26]. Neovascular membrane expression of these MMPs indicates their active involvement in the angiogenesis observed in diabetic retinopathy [21].

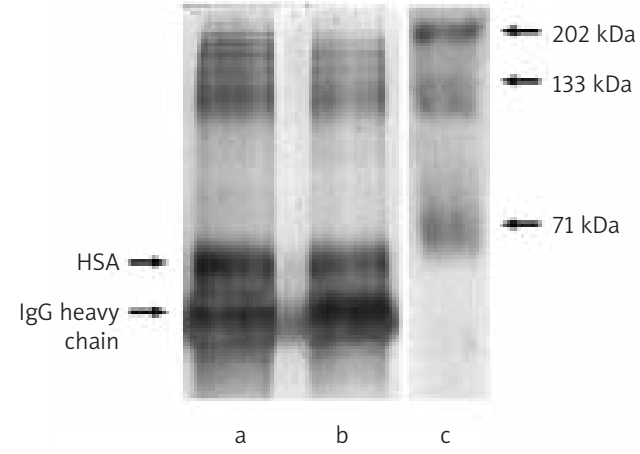

Lanes: (a) plasma proteins; (b) aqueous humour proteins; (c) molecular mass standards

Figure 5. Electrophoretic separation of the aqueous humour samples (only upper part of the gel is presented)

An interesting aspect raised by some reports is the cellular source of MMPs affecting the elevation of these enzymes in PDR eyes. Increased levels of active MMP-9 and pro-MMP-9 were found in vitreous humour of diabetic patients with PDR and vitreous haemorrhage [10]. The same study showed a strong correlation between MMP-9 levels and haemoglobin levels, suggesting that it may be simply the result of blood protein being found in the cavity of vitreous humour, leaving however the possibility that MMP-9 is involved actively in the process of vitreous haemorrhage or a disease stage shortly preceding it. Thus in our study we excluded patients with active vitreous haemorrhage and also patients who previously underwent vitrectomy for diabetic vitreous haemorrhage. It is known that one of the early features of diabetic retinopathy is breakdown of the blood-retina barrier. It results in vascular permeability in the retina and the development of retinal oedema. These findings suggest that elevated expression of MMPs in the aqueous humour may facilitate an increase in vascular permeability [12]. In this connection we did not exclude the possibility that MMP-2 and MMP-9 (in a few samples of aqueous humour of PDR patients) were at least in part derived from plasma. Our investigations showed a trend to correlation between MMP-2 activities in aqueous humour of our patients and total protein concentrations.

On the other hand, electrophoretic analysis of aqueous humour and plasma proteins showed a similar pattern. Abundant plasma proteins of molecular mass comparable to MMP-9 and higher (up to $200 \mathrm{kDa}$ ) were clearly visible in aqueous humour samples. Then, if MMP-2 activities in aqueous humour were derived exclusively from plasma, MMP-9 activities should also be visible in all aqueous humour samples on zymographic gels. This is highly suggestive that MMP-2 may be 
overexpressed in PDR eyes by yet unidentified cells. It remains an open question in what proportion loss of the blood aqueous humour barrier contributes to the findings of increased MMP levels. But more likely presence of MMP-9 only in some samples of PDR patients seems to be a reflection of the selective activation of MMP-9 at a certain disease stage.

Angiogenesis plays an important role in many disease processes throughout the body, including cancer and diabetic retinopathy. It is often assumed that new vessel formation is identical in all contexts. However, there is much evidence suggesting that ocular angiogenesis may differ from angiogenesis elsewhere in the body [27]. For example, TIMP 1 is able to inhibit angiogenesis in some tissues, including cancer, but stimulates it in the retina [28], and similarly, despite the fact that MMP-9 is needed for cancer angiogenesis [29], MMP-2 but not MMP-9 is essential in the regulation of retinal neovascularization [5]. Thus, the augmented MMP-2 activities observed by us in aqueous humour of PDR patients may reflect participation of this enzyme in retinal neovascularization.

Although the small group of patients included in this study does not allow us to draw definitive conclusions, the results described herein support the hypothesis that MMP-2 but not MMP-9 may be of particular importance in diabetic retinal neovascularization.

\section{Acknowledgments}

This study was supported by grant No. 502-11-539 from the Medical University of Lodz. None of the authors has any proprietary interest in the products mentioned in the paper.

\section{References}

1. Hrabec E, Stręk M. Human matrix metalloproteinase family: domain structure, substrate specificity and their expression pattern in normal and cancer cells. Curr Pneumol 1997; 1: 73-85.

2. Hrabec E, Naduk J, Stręk M, Hrabec Z. Type IV collagenases (MMP-2 and MMP-9) and their substrates-intracellular proteins, hormones, cytokines, chemokines and their receptors. Postepy Biochem 2007; 53: 37-45.

3. Zhang G, Fahmy RG, diGirolamo N, Khachigian LM. JUN SiRNA regulates matrix metalloproteinase-2 expression, microvascular endothelial growth and retinal neovascularisation. J Cell Sci 2006; 119: 3219-26.

4. Gondi CS, Lakka SS, Dinh DH, Olivero WC, Gujrati M, Rao JS. Downregulation of UPA, UPAR and MMP-9 using small, interfering, hairpin RNA (siRNA) inhibits glioma cell invasion, angiogenesis and tumor growth. Neuron Glia Biol 2004; 1: 165-76.

5. Ohno-Matsui K, Uetama T, Yoshida T, et al. Reduced retinal angiogenesis in MMP-2-deficient mice. Invest Ophtalmol Vis Sci 2003; 44: 5370-5.

6. Vu TH, Werb Z. Matrix metalloproteinases: effectors of development and normal physiology. Genes Dev 2000; 14: 2123-33.
7. Rundhaug JE. Matrix metalloproteinases and angiogenesis. J Cell Mol Med 2005; 9: 267-85.

8. Notari L, Miller A, Martinez A, et al. Pigment epitheliumderived factor is a substrate for matrix metalloproteinase type 2 and type 9: implications for downregulation in hypoxia. Invest Ophtalmol Vis Sci 2005; 46: 2736-47.

9. Zucker S, Mirza H, Conner CE, et al. Vascular endothelial growth factor induces tissue factor and matrix metalloproteinase production in endothelial cells: conversion of prothrombin to thrombin results in progelatinase A activation and cell proliferation. Int J Cancer 1998; 75: 780-6.

10. Descamps FJ, Martens E, Kangave D, et al. The activated form of gelatinase B/matrix metalloproteinase- 9 is associated with diabetic vitreous hemorrhage. Exp Eye Res 2006; 83: 401-7.

11. Jacqueminet $\mathrm{S}$, Ben Abdesselam O, Chapman MJ, et al. Elevated circulating levels of matrix metalloproteinase-9 in type 1 diabetic patients with and without retinopathy. Clin Chim Acta 2006; 367: 103-7.

12. Giebel SJ, Menicucci G, McGuire PG, Das A. Matrix metalloproteinases in early diabetic retinopathy and their role in alteration of the blood-retinal barrier. Lab Invest 2005; 85: 597-607.

13. Ohnishi ST, Barr JK. A simplified method of quantitating proteins using the biuret and phenol reagents. Anal Biochem 1978; 86: 193-200.

14. Hrabec E, Stręk M, Nowak D, Greger J, Suwalski M, Hrabec Z. Activity of type IV collagenases (MMP-2 and MMP-9) in primary pulmonary carcinomas: a quantitative analysys. J Cancer Res Clin Oncol 2002; 128: 197-204.

15. Laemmli UK. Cleavage of structural proteins during the assembly of the head of bacteriophage T4. Nature 1970; 227: 680-5.

16. Wray W, Boulikas P, Wray VP, Hancock R. Silver staining of proteins in polyacrylamide gels. Anal Biochem 1981; 118: 197-203.

17. Hrabec E, Stręk M, Zięba M, Kwiatkowska S, Hrabec Z. Circulation level of matrix metalloproteinase- 9 is correlated with disease severity in tuberculosis patients. Int J Tuber Lung Dis 2002; 6: 713-9.

18. Leber TM, Balkwill FR. Zymography: a single step staining method for quantification of proteolytic activity on substrate gels. Anal Biochem 1997; 249: 24-8.

19. Hrabec E, Stręk M, Nowak D, Hrabec Z. Elevated levels of circulating matrix metalloproteinase- 9 in patients with lung cancer. Respiratory Medicine 2001; 95: 1-4.

20. Noda K, Ishida S, Inoue M, et al. Production and activation of matrix metalloproteinase- 2 in proliferative diabetic retinopathy. Invest Ophthalmol Vis Sci 2003; 44: 2163-9.

21. Salzman J, Limb A, Khaw P, et al. Matrix metalloproteinases and their natural inhibitors in fibrovascular membranes of proliferative diabetic retinopathy. J Ophthalmol 2000; 84: 1091-6.

22. De La Paz MA, Itoh Y, Toth CA, Nagase H. Matrix metalloproteinases and their inhibitors in human vitreous. Invest Ophthalmol Vis Sci 1998; 39: 1256-60.

23. Kosano H, Okano T, Katsura Y, et al. ProMMP-9 (92 kDa gelatinase) in vitreous fluid of patients with proliferative diabetic retinopathy. Life Sci 1999; 64: 2307-15.

24. Jin M, Kashiwagi K, lizuka Y, Tanaka Y, Imai M, Tsukahara S. Matrix metalloproteinases in human diabetic and nondiabetic vitreous. Retina 2001; 21: 28-33.

25. Sethi CS, Bailey TA, Luthert PJ, Chong NH. Matrix metalloproteinases biology applied to vitreoretinal disorders. J Ophthalmol 2000; 84: 654-66. 
26. Das A, McGuire PG, Eriqat C, et al. Human diabetic neovascular membranes contain high levels of urokinase and metalloproteinase enzymes. Invest Ophthalmol Vis Sci 1999; 40: 809-13.

27. Campochiaro PA. Ocular versus extraocular neovascularization: mirror images or vague resemblances. Invest Ophthalmol Vis Sci 2006; 47: 462-74.

28. Yamada E, Tobe T, Yamada H, et al. TIMP-1 promotes VEGF-induced neovascularization in the retina. Histol Histopathol 2001; 16: 87-97.

29. Kong D, Li Y, Wang Z, Banerjee S, Sarkar FH. Inhibition of angiogenesis and invasion by $3,3^{\prime}$-diindolylmethane is mediated by the nuclear factor-kappaB downstream target genes MMP-9 and UPA that regulated bioavailability of vascular endothelial growth factor in prostate cancer. Cancer Res 2007; 67: 3310-9. 